\title{
Study Abroad As a Transformational Experience and Its Effect upon Study Abroad Students and Host Nationals in Santiago, Chile
}

\author{
Sk y e stephe ns o n \\ CIEE Resident Director, Santiago,Chile
}

\section{Introduction}

In the last decade, increasing numbers of students have chosen to study abroad. An underlying premise of many of these programs to "nontraditional destinations" is that exposure to these often quite different cultures and living conditions promotes a more positive understanding of the "other." To date, however, there has been little analysis of the actual impact of the study abroad experience upon participants' cultural perceptions and personal values. What aspects of values appear to change the most as a result of study abroad? How do interactions with host nationals affect the students' views of both themselves and the "other"? Does the presence of foreign students affect members of the host society who have extended contact with them? Is the outcome of the exchange experience in terms of cross-cultural understanding any different for participants in study abroad programs located in countries with lower living standards than their home?

The purpose of this study is to examine the questions raised above in one specific setting-Santiago, Chile. It explores the effect that the study abroad experience has had upon three distinct groups' cultural perceptions and personal values: the study abroad students themselves, their Chilean host families, and selected university professors. In 1988, all three groups were asked to fill out a questionnaire drafted by a bi-national 
group of researchers. ${ }^{1}$ Follow-up interviews were conducted to gain greater specificity. While the author is fully aware of the difficulties in attempting to "measure" via questionnaires such complex areas as values and cultural views, it is her belief that it is precisely this complexity which makes such research-however flawed-valuable.

Three premises underlie this pilot study. The first involves the issue of value change. It is usually assumed that the study abroad experience necessarily leads to the promotion of more positive views of the "other." While the experience is often a transcendental one for many young people, whether the sojourner returns home with a more positive, more negative or mixed view of the host culture depends upon a variety of factors. Such factors include, among others, the "fit" between the student's personal attributes and the programmatic realities and cultural patterns of the study abroad destination. Perhaps it is naïve to assume that study abroad program participation necessarily leads to more positive views of the "other."

The idealists regard it as self-evident that educational exchange must lead to improved international relations. They take it for granted that cross-cultural contact, particularly among young people, creates mutual understanding and when these students in the fullness of time assume positions of influence in their societies, this will be reflected in barmonious relations between their respective countries, and thus contribute to world peace. The evidence ... indicates that the connection between inter-group contact and inter-group attitudes is very complex, such that contact may either increase or reduce mutual tolerance and understanding, depending on a very large matrix of interaction variables. Indeed, there have been instances where educational exchange has led to a worsening of cross-cultural attitudes. ${ }^{2}$

The second premise is that it is important to broaden the scope beyond that of the study abroad student himself/herself. While the sojourner naturally undergoes changes in value orientation and perceptions, it is not a one-way process. Members of the host society can be affected by the experience as well. As Adrian Furnham and Stephen Bochner put it, "all contact has two-way reciprocal consequences, although the extent to which each party is affected by the interaction depends on a variety of factors. To ascertain better the true impact of the 
exchange experience, it is necessary to consider both the exchange students themselves and the receiving groups in the host culture." ${ }^{3}$

The last premise of this study is that there are country specific conditions that can affect the final outcome of the study abroad experience. Among such factors are the nation's historical realities, economic conditions, openness to foreigners, the university environment, cultural practices and beliefs, etc. It is important to have a better understanding of these realities when setting up and running an overseas program. While there has been a proliferation of overseas programs in Chile in recent years, there has been no published research to date on Chilean culture and society and their influence on the educational experience of US students. The following two sections will highlight those aspects of Chilean reality most significant for the field of international education.

\section{Chilean Culture: An Overview}

Chileans are proud of noting that their country is "at the end of the world," as they put it. Quite literally, this string bean of a nation is located at the very bottom of the South American peninsula. It is bordered on the north by the driest desert in the world, on the south by the Antarctic, on the east by the second-highest mountain range, and on the west by the largest ocean. In many ways, Chile resembles more an "island" than a continental appendage.

In cultural terms as well, Chileans demonstrate an "island mentality." There tends to be a strong sense of what is "Chilean" in this relatively homogenous and centralized nation of less than 14 million people. Historical factors as well have tended to create a cohesive and integrated country. Chile was one of the least important parts of the Spanish Empire, as it had little natural wealth and was extremely difficult to get to. As a result, only the most adventurous - or perhaps the most foolhardyarrived in Chile during the early period of Spanish colonization. Those few who did make it across the inhospitable Atacama desert and the lofty Andes mountains found themselves face-to-face with one of the fiercest groups of native peoples in the Americas-the Mapuches.

These indigenous peoples, the predominant group from the middle of Chile south, managed to fight off the European onslaught for nearly three hundred years. They were never formally defeated, but rather paci- 
fied in the 1880s with the signing of a peace treaty. During these centuries of frontier conflicts, there were not massive waves of European migration to Chile as occurred in some other nations of the hemisphere. Most of the Europeans who arrived in Chile were of Spanish or Portuguese descent.

With the pacification of the native peoples, much of the south of Chile was opened up for colonization. In an attempt to recruit "hardworking" stock, the Chilean government of the time actively encouraged German colonization of the Puerto Montt region. Germans, particularly from the largely Catholic areas in southern Germany, were offered attractive incentives to migrate to Chile. This group, while not numerically large, has had a significant role in twentieth-century Chile. In the Chilean dialect, certain German words can be noted such as "kuchen" for cake. More significant was the German role in the formation of the Chilean military, which continues to have a decidedly "Prussian" stamp even today.

Along the coast of Chile, in the port cities of Punta Arenas and Valparaiso, the impact of migration in the nineteenth century was also significant. Before the building of the Panama Canal, all the ships that journeyed from the Atlantic to the Pacific had to go through either the Drake passage or around the Cape of Horn. It was a hazardous trip, and ships usually stopped in Chilean ports to rest and stock up before continuing up the coast. Some sailors decided to stay in Chile. This was particularly true of the English in Valparaiso and the Croatians in Punta Arenas.

Notwithstanding the arrival of the aforementioned groups to Chile, this nation received much less immigration than did Argentina. ${ }^{4}$ Nor did Chile have large numbers of indigenous peoples, like its northern neighbors Peru and Bolivia. Chile did not even host many blacks, and those few that did arrive seem to have merged into the general Chilean populace. ${ }^{5}$

Consequently, most of the Chileans today are a mixture of the European colonists and the indigenous Mapuches. Although many, especially in the middle- to upper-classes, refuse to acknowledge the possibility of harboring Indian ancestry, recent scholarship has shown that Chile is primarily a nation of mixed ancestry. ${ }^{6}$ Nonetheless, compared to the Andean nations, one feels the Indian presence much less. According to census figures, less than $10 \%$ of Chileans are Indian.?

Due to these unique historical and geographical patterns, many Chileans have had little exposure to culturally and ethnically different 
people. This isolation was exacerbated during the 1973 to 1988 period when, due primarily to political factors, Chile was cut off from much international contact. While the return to democracy in 1988 has served to open the country to increasing foreign investment and "cross-cultural exchanges," the legacy of the years of repression and censorship are still felt in Chilean society today.

There is a strong sense of "insider" versus "outsider," with the term "gringo" frequently employed to describe non-Chileans, particularly those with a light complexion. The emphasis is often upon the group, rather than the individual, leading some to call it a "herd mentality." Close-knit support groups follow most Chileans throughout their lifetime, starting with their extended nuclear family and often including school mates and work partners.

Chileans are known for being decidedly less verbal than their neighbors the Argentines; much of their communication is done non-verbally. There are certain cultural clues that all Chileans know, particularly ways to categorize social class, which is extremely important in Chile. Clothing, accent, even school can serve to "place" a Chilean in a certain social milieu. Chileans themselves frequently state that they are not racist, but they are classist.

There is a well-known saying that "Chileans are the English of Latin America." While still exhibiting certain "Latin characteristics," Chileans nonetheless are proud of not being so "tropical," as they put it. After all, they recently selected the penguin as their national mascot to show that they are a "cool" nation. Most Chileans define themselves as hard-working, family oriented, class-conscious and conservative. The enormous role that the Catholic Church has had in shaping values in contemporary Chile should not be overlooked. In fact, today Chile is the only nation in the western world that does not have a divorce law. Topics such as abortion and homosexuality are "taboo" for many sectors of the population.

In other ways, however, Chile is a modern and open society. It was the first Latin American nation to pursue neo-liberal economic policies beginning in the 1970s. The fruits of its economic success can be seen everywhere today. They are most notable in certain affluent neighborhoods, which in many ways seem much like California, complete with Pizza Hut, McDonald's and big shopping malls.

One of the most difficult issues facing Chileans today concerns 
national identity. Many sense that there has been so much rapid change in recent years that something intrinsically Chilean has been lost in the process. When dealing with individuals from the United States, many Chileans seem ambivalent in how to judge the "cross-cultural interchange." They often exhibit a combination of a sense of inferiority, noting the many positive aspects and consumer goods coming from the United States, while at the same time harboring a conviction that Chilean culture and lifestyle is "better" for them, particularly in the areas of family and social values.

For the overseas student in Chile, a different phenomenon often occurs. The initial impression is that Chile seems much more like the United States than the participant might have thought before arriving. The assumption is then made that the Chileans must be similar to the people from the United States. The student then acts upon this fallacious assumption, finding that behavioral patterns and values can be quite different. Particularly in the areas of political views, opinions on social and racial issues, and perceptions of class, the student often finds himself/herself surprised that Chileans who seem so "normal" could have views that are so "politically incorrect."

\section{The Chilean University and International Educational Programs}

Despite Chile's insular history, this Andean nation has been the host to numerous foreign intellectuals and students over the centuries. Because of its political stability and reputation for hospitality, many foreigners, primarily Latin Americans fleeing persecution in their native land, found a warm reception in Chile. Two of the individuals instrumental in founding and consolidating the Universidad de Chile-the oldest and most important public university in Chile-were of foreign descent. One was Andres Bello, a Venezuelan, and the other was Domeyko, an immigrant of Polish descent.

The university system that was set up in Chile borrowed heavily from the French model of higher education. Numerous facultades were set up within the university, each one relatively autonomous in terms of student selection and training. Even today, the university is considered primarily a center for professional training, with a student entering a specif- 
ic facultad as a freshman and remaining there throughout his/her university program. Attrition rates are high and degree requirements tend to be quite rigid, with little time allotted for electives.

The Universidad de Chile was founded in 1842 as a public university open to qualified individuals of all the social sectors. It replaced the Real Universidad de San Felipe that had existed during the colonial period. For several decades, it was the only university in Chile, and one of the best in South America. The list of graduates from this institution is extensive and impressive, and its role as a means for social mobility within a relatively hierarchical and class-oriented nation such as Chile has been crucial.

The Pontificia Universidad Católica de Chile was founded several decades after the Universidad de Chile, in 1888. It was established for the purpose of providing a Catholic-oriented and private alternative for higher education. Its role in the formation of elites has also been crucial. Perhaps its most well-known contribution in recent years has been through the training of the so-called "Chicago boys." These Católica economic students studied at the University of Chicago under the auspices of an exchange agreement. Some even were taught by Milton Friedman himself. Upon their return to Chile, several were instrumental during the Pinochet years in conceptualizing and implementing the neo-liberal economic reforms.

Despite the agreements that permitted Chileans to receive advanced training abroad, ${ }^{8}$ until this decade non-degree overseas students were practically non-existent in Chilean universities. Several concomitant phenomena coincided in the early 1990s to promote interest in starting up exchange programs at Chilean universities. The "pull factors" included the nation's return to democracy, its stability and prosperity, and the solid reputations of both the Universidad de Chile and the Pontificia Universidad Católica.9 Among the "push factors" in the United States were the increasing interest in "non-traditional" destinations for study abroad, the burgeoning of ethnic and Latin American studies, and the recent emphasis at many institutions on the "internationalization of education."

In 1990, the first group of students from a US university, Stanford, arrived to study at the Universidad Católica. Due to the trimester schedule at Stanford, they were not able to take the semester courses at the uni- 
versity, and instead took special courses at the campus. The State University of New York at Plattsburgh underwrote in 1991 the first group of students to take regular classes at a Chilean university. A short while later, the Council on International Educational Exchange also established a program at both the Universidad Católica and the Universidad de Chile.

For all three of these study abroad programs, Chilean academics based in the United States played a pivotal role in their establishment. For Stanford University, it was a Chilean sociologist-Edmundo Fuenzalida—who was instrumental in arranging the first ever agreement. At SUNY/Plattsburgh, a Latin American specialist-William Culvert, who had lived in Chile during the 1960s and was married to a Chileanpushed through the first direct enrollment program. The Council on International Educational Exchange garnered help from a Chilean scholar at Georgetown University: Arturo Valenzuela.

An indication of the lack of experience on the part of the Chilean universities in receiving short-term, non-degree-seeking overseas students can be noted in the following anecdote: According to Francisco Lara, the current Coordinator of Foreign Students at the Universidad de Chile, when William Culvert of SUNY Plattsburgh began to inquire about setting up a study abroad program at the Universidad de Chile there was no one to receive him. Consequently, a new office had to be created.

Following the success of these programs, others soon followed..$^{10} \mathrm{By}$ 1992 both universities had well-run offices for international exchanges staffed with competent individuals well able to promote institutional interests. At the Universidad Católica, an extensive campaign to internationalize was carried out. One component involved the arranging of both bilateral and unilateral (for pay) exchanges. To give an idea of the expansion of foreign students, in 1990 there were two exchange programs from one sending nation-the United States. Thirty-seven students in total participated. Eight years later, over 460 students per year studied at the Universidad Católica in a "special status." These students came from universities located in seventeen different nations. The total number of exchange students who studied at the Pontificia Universidad Católica from 1991 to 1998 is over 2,500.

The Universidad de Chile, while expanding enrollment of exchange students as well, has not had the growth of the Católica. From 1991 to 
1998, over 1,860 non-degree students studied at the Universidad de Chile, about $80 \%$ coming from United States-based universities. The smaller number of exchange students at the Universidad de Chile is due to several factors. The first is of an institutional nature. The Universidad de Chile is government funded and controlled, giving it less autonomy and flexibility in setting up programs. During the many years of authoritarian rule, it was consciously underfunded by the government and thus, at present, offers less "amenities" (i.e., computers, e-mail, and good sports facilities) than the Católica. A second factor is the policy on the part of Universidad de Chile authorities not to overtax their services for international students by enrolling too many.

\section{The Effect of the Study Abroad Experience upon the Students}

Due to the author's affiliation with the Council program, the research for this study was carried out with the Council student participants in Santiago, Chile. During the first semester of 1998, they were asked to fill out a questionnaire immediately upon their arrival and a second one shortly before their departure. There was a five-month time-span between these two periods. The purpose of the questionnaires was to find out: (1) in what ways, if any, the students' initial expectations differed from their actual experiences; and (2) how their opinions of Chilean culture changed during their stay.

In total, 52 students completed the questionnaires. Due to the fact that Council is a consortium-program, the respondents came from colleges and universities located throughout the United States. The greatest numbers were from Georgetown University, followed by the University of Colorado. Other schools represented included Princeton University, Brown University, the University of Pennsylvania and Hope College, among others. As usual, there were more female than male participants in the program: 17 were male and 35 were female.

In terms of ethnic affiliation, 36 defined themselves as white, while the second largest group was the Hispanic, with eight students. There were two Black students, two Jewish students, two Asians and one Native American. One student was difficult to define ethnically-he was halfChilean, a quarter Japanese and a quarter Caucasian. He had grown up in 
Tokyo, but went to school in the United States.

Included in the questionnaire was a section on previous international experience. The author felt that there might be some relationship between a student's earlier cross-cultural experiences and the ease/difficulty they might have in adjusting to life in Chile. It is also possible that the students of Latin descent, several of whom actually had lived in other Latin American nations previously, and all of whom spoke Spanish in their home, might find the quality of their experience different. Out of the 52 students, the Council program was a first cross-cultural experience for seven of them. Twenty had spent a month or less outside of the United States, while 20 others had spent from a month to a year abroad. Three had lived for more than one year in another country.

The students were asked to indicate the ease or difficulty they expected to experience (arrival) or had experienced (departure) in adapting to or accommodating a variety of situations and value orientations. Forty items were listed, with the scale being: $0=$ not applicable $1=$ very easy 2 =easy 3 =average 4 =difficult 5 =very difficult. The items were organized in clusters of five, representing a particular theme. The issues explored were life in Santiago, the host family situation, social activities, using the Spanish language, the university/classroom environment, cultural differences, and opinions/beliefs.

Table \#1 shows all situations/value changes to which the students anticipated they would have an average to a difficult time adjusting. As can be noted, the two situations that the students thought would prove to be the most difficult involved language use-“understanding jokes, humor in Spanish" and "understanding Chilean professors." Worry about academic issues were also noted in the high ranking given "registering for courses." Also, they worried about making Chilean friendships. The only area regarding values/beliefs that they anticipated as being possibly difficult to adjust to concerned the question of race and ethnicity. 


\section{Table 1 \\ Situations/value changes students anticipated would be average or above average in difficulty of adjustment}

(Scale: $0=$ not applicable $1=$ very easy 2 =easy 3-average 4-difficult 5-very difficult)

\begin{tabular}{lc}
\hline & Average Score \\
Understanding jokes, humor in Spanish & 3.5 \\
\hline Understanding Chilean professors & 3.2 \\
\hline $\begin{array}{l}\text { Respecting/adjusting to Chilean } \\
\text { opinions/beliefs regarding race issues }\end{array}$ & 3.2 \\
\hline Making Chilean friendships & 3.0 \\
\hline Registering for courses & 3.0 \\
\hline
\end{tabular}

When contrasted with Table \#2, which shows all the situations/value changes that the students found to have been actually difficult to adjust to, one striking factor comes through. The experience seems to have been more stressful than anticipated, for the students upon departure listed 17 areas that they had either an average or high degree of difficulty in adjusting to. Not only striking is the increase in numbers of items, but also the areas cited as being most difficult. While upon arrival they seemed most concerned about their use of Spanish, upon departure only one of the 17 areas of difficulty was in language-that of understanding jokes in Spanish. Concern about understanding professors dropped off the chart.

The areas that emerge as most difficult to adjust to in Table \#2 fell into three distinct groups-beliefs/values/cultural differences, social interactions and the university environment. A few items such as the pollution problem (rated as the most difficult of all) might be particular to the Chilean case.

Respecting/adjusting to Chilean opinions/beliefs regarding class issues, race issues, and gender/sexual orientation issues were all considered difficult to adjust to by the students. Also mentioned as stressful were adjusting to different uses of time and to the food. 
Table 2

Situations/value changes students ranked upon departing as average or above average in difficulty of adjustment

(Scale: $0=$ not applicable $1=$ very easy 2 =easy 3-average 4-difficult 5-very difficult)

\begin{tabular}{ll}
\hline & Average Score \\
\hline Adjusting to smog/pollution problems & 4.0 \\
\hline $\begin{array}{l}\text { Respecting and/or adjusting } \\
\text { to Chilean opinions regarding class issues }\end{array}$ & 3.9 \\
\hline Understanding jokes, humor in Spanish & 3.6 \\
\hline Registering for courses & 3.6 \\
\hline Understanding the Chilean university system & 3.5 \\
\hline Making Chilean friends & 3.5 \\
\hline Interacting with Chilean students on campus & 3.5 \\
\hline $\begin{array}{l}\text { Adjusting to different } \\
\text { patterns of male/female dating behavior }\end{array}$ & 3.4 \\
\hline $\begin{array}{l}\text { Respecting and/or adjusting } \\
\text { to Chilean opinions/beliefs regarding race issues }\end{array}$ & 3.4 \\
\hline Appearing a foreigner, standing out, feeling different & 3.3 \\
\hline Adjusting to the food and use of food in the host family & 3.3 \\
\hline Adjusting to the Chilean teaching/learning style & 3.3 \\
\hline Maintaining academic standards & 3.2 \\
\hline Adjusting to different uses of time (punctuality, etc.) & 3.2 \\
\hline $\begin{array}{l}\text { Adjusting to Chilean opinions/beliefs } \\
\text { regarding gender/sexual orientation issues }\end{array}$ \\
\hline Communicating needs to the host family & 3.2 \\
\hline of male/female friendship behavior & 3.1 \\
\hline
\end{tabular}

Appearing as a foreigner/standing out was ranked quite high in terms of degree of difficulty of adjustment. Despite the fact that some of the students blended into Chilean society relatively easily in terms of physical appearance, others felt uncomfortable with the attention they received due to their obvious "foreignness." This illustrates, as some of the other characteristics noted above, the relatively insular nature of Chilean society. For many Chileans, seeing an "outsider" is still a rare occurrence. Even behaviors that some students exhibited such as using a certain brand 
of backpack and having numerous pierced earrings immediately marked them as a non-Chilean.

There seems to be both a gender and an ethnic component to how the students felt about standing out. Among the students who classified themselves as Hispanic, not one indicated experiencing either "difficulty" or "great difficulty" in being a foreigner in Chile. In examining the distribution of answers in terms of gender, an interesting pattern emerges. Among the males, 25\% felt they had no difficulty, 37\% felt they had little difficulty, $37 \%$ felt they had some difficulty and only $2 \%$ indicated feeling quite a bit of difficulty as a foreigner. For the women, the figures were quite different. Only one person (3\%) said she felt no difficulty, while $27 \%$ had little difficulty and $35 \%$ experienced some difficulty. The remaining $35 \%$ of the female students had quite a bit of difficulty adjusting to standing out in Chile. Twenty-one percent felt that it was quite difficult and $14 \%$ found that it was extremely difficult. The two black participants, both females, indicated feeling extreme unease in Chile.

When considering social interactions, making Chilean friends did emerge as difficult, just as anticipated. Other social situations that were also stressful for many of the students during their stay in Chile were interacting with Chilean students on campus, adjusting to different patterns of male/female dating behavior, and adjusting to different patterns of male/female friendship behavior. In the host family situation, the only area ranked as being difficult was that of the student communicating his/her needs to the host family.

The great differences between the United States and the Chilean university systems can be noted in the fact that understanding the Chilean university system, registering for courses, and adjusting to the Chilean teaching/learning styles were all considered difficult by the students. This is not surprising given the different structures and "cultures" of the university systems of the two nations. Not only do the Chilean universities not have the kind of campuses and student support that most United States universities do, but in addition many of the professors are part-time and often come only sporadically to the university. The United States students tended to find many of their Chilean classes too "unstructured," and with more emphasis upon memorization and less upon creativity than they were used to.

The gap between the students' initial expectations and their percep- 
tion of the actual experience is shown in Tables \#3 and \#4. These charts corroborate the evidence presented above. Upon arrival, the students' most immediate concern was using the Spanish language. However, as the exchange experience transpired and they lived in the Chilean culture, they found that cultural and value orientation differences to be more difficult to adjust to. Table \#3 shows the only three areas where there was an actual drop in the degree of difficulty assigned by the students between their arrival and their departure. As can be seen, all three listed-understanding Chilean professors, using Spanish in the classroom and using Spanish in a non-academic setting-deal with language use.

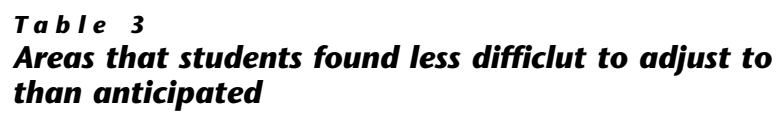

\begin{tabular}{ll}
\hline & Decrease \\
\hline Understanding Chilean professors & 0.45 \\
\hline Using Spanish in the classroom/academic setting & 0.3 \\
\hline Using Spanish in a non-academic setting & 0.1 \\
\hline
\end{tabular}

Table \#4 lists the nine situations/value orientations in which there was the biggest increase between the students' initial expectations of the degree of difficulty and the actual degree of difficulty that they found in adjusting. Discarding the smog/pollution issue, all the others clearly deal with opinions and cultural differences. "Keeping an open mind about Chilean culture" was considered much more difficult by the students then they had expected, as was "maintaining a clear concept of your personal beliefs" and "changing personal beliefs as a result of your experience." Views concerning social class came through again as significant-showing the very different nature of social class between United States and Chilean societies. Other areas that the students found were more difficult then they had anticipated were "use of time," "food," and "standing out."

Several of the same patterns emerged in the students' responses to ten open questions included in the questionnaire. They were asked what they expected to find (arrival) or had found (departure) in such areas as culture/values, the host family, academics, language, life in Santiago, friendship and views of Chileans. In the data analysis, the emphasis was 
placed on the difference between the students' initial ideas upon arrival and their perspectives upon departure.

\section{Table 4 \\ Top nine areas that students found more difficult to adjust to than anticipated}

(Number in column indicates difference between arrival and departure averages)

\begin{tabular}{ll}
\hline Keeping an open mind about Chilean culture & Increase \\
\hline $\begin{array}{l}\text { Respecting and/or adjusting to } \\
\text { Chilean opinions/beliefs regarding class issues }\end{array}$ & 1.2 \\
\hline Adjusting to the smog/pollution problems & 1.2 \\
\hline Adjusting to the different uses of time (punctuality, etc.) & 0.9 \\
\hline Appearing a foreigner, standing out, feeling different & 0.7 \\
\hline Adjusting to the food and use of food in the host family & 0.6 \\
\hline Maintaining a clear concept of one's personal beliefs & 0.6 \\
\hline Changing personal beliefs & 0.6 \\
\hline Un a result of one's experience in Chile & 0.6 \\
\hline
\end{tabular}

In response to the question, "I expect that my greatest challenge to the Chilean culture/lifestyle will be ...," six students indicated the language barrier. However, upon departure not one student said that it had been their greatest challenge. The areas that were most frequently mentioned were living in a big city (transportation, noise, etc.) and cultural/value issues such as lack of organization/schedules, machismo/sexism, and the Chilean perspective on social class.

Some of the students' responses on the departure questionnaire were as follows: "My greatest challenge has been dealing with the lack of ethnic diversity." "I find it hard to deal with indirectness; Chileans just can't come out and say things like I and other Americans do." "It has been hard dealing with the different economic levels and with what is appropriate or not compared to the US." "I do not feel the same about being a woman in Chile because I really don't know what that means here."

Another question explored a related theme, which was that of respecting Chilean beliefs. The exact wording was as follows: "I expect (have found) that my greatest challenge to respecting Chilean beliefs will 
be (has been)... ." Upon arrival the students ranked sexism, being openminded and religious differences the highest. Upon departure, the religious issue was not mentioned by anyone, being replaced by the class orientation of Chilean society.

Some of the student comments underlined the learning process that they had gone through as a result of the study abroad experience. One student had this to say: "my greatest challenge was just learning that it is hard to change ideas of groups of people when they don't have experience with other cultures." Another said, "it was hard to understand and tolerate the discrimination and prejudice of Chilean culture. Most outstanding being ideas of humor-racial and sexual." Yet another questioned her own acceptance when she responded, "my greatest challenge has been that I am not sure yet if I can respect Chilean beliefs."

The greater understanding and knowledge of Chilean culture that the students acquired as a result of the study abroad experience affected their views of Chileans in general. While their initial expectations were that Chileans would be open, friendly and sociable ( 35 used these words) but also a bit shy and conservative, upon leaving the majority still found Chileans to be very warm and hospitable (34 students). However, other descriptions of Chileans were also included that were not always so positive. Among some of the characteristics most frequently cited were, "poorly informed, little knowledge of the other, close-minded," "nationalistic and ethnocentric," "not friendly, cold" and "rude."

Several students pointed out how difficult it was to answer this question. One said, "Chileans tend to be just as diverse, complicated, simple, loving, selfish, brilliant, ignorant, shy, loud, and fascinating as any other group of people." Another person said, "Chileans are like everyone else in the world. They vary and I don't see a lot of generalizations worth making."

\section{The Effect of the Study Abroad Experience upon Host Families}

Host families were asked to fill out a questionnaire in May 1998 that explored the impact of hosting a US student. Several dimensions were examined, including the effect upon the household in general, relations among family members, and changes in their own personal values/beliefs. 
The fact that the Council Study Center staff administered the questionnaire could have partially biased the results; it is possible that some host families might have presented an excessively positive view of the host experience in order to give a "good impression" rather than a "realistic one." Not withstanding this caveat, it is the contention of the author that some valuable information - especially in the area of value change-was gained through the survey.

Fifty-six individuals responded to the survey, a nearly total response rate. Of those who responded, almost all were the "host mothers." Their composite profile is as follows: $65 \%$ had a university degree or beyond, over half were engaged in some type of work outside the house, and about $20 \%$ had lived outside of Chile at some point in their life.

In the questionnaire, the families were asked to list three advantages and three disadvantages of hosting study abroad students. Their responses can be seen in tables \#5 and \#6. Concerning the advantages of hosting foreign students (Table \#5), the most common advantage given (44\% of the total responses) was "cultural reasons." Other advantages mentioned were "promoting cultural understanding and exchange," "learning English," "teaching the student more about Chile and Chilean culture," and "gaining a better understanding of US culture."

The next most important category indicated by the respondents were "social reasons" (31\%), including companionship, friendship, "having another 'child,' " and other social reasons. This category was followed by economic factors (10\%), and family reasons $(6 \%)$. About $9 \%$ indicated other reasons for serving as a host family, such as improving communication, learning from the student, and contact with the student's family. Only $2 \%$ out of the total gave a broad view of the experience-indicating its importance in promoting pluralism and humanitarianism. 


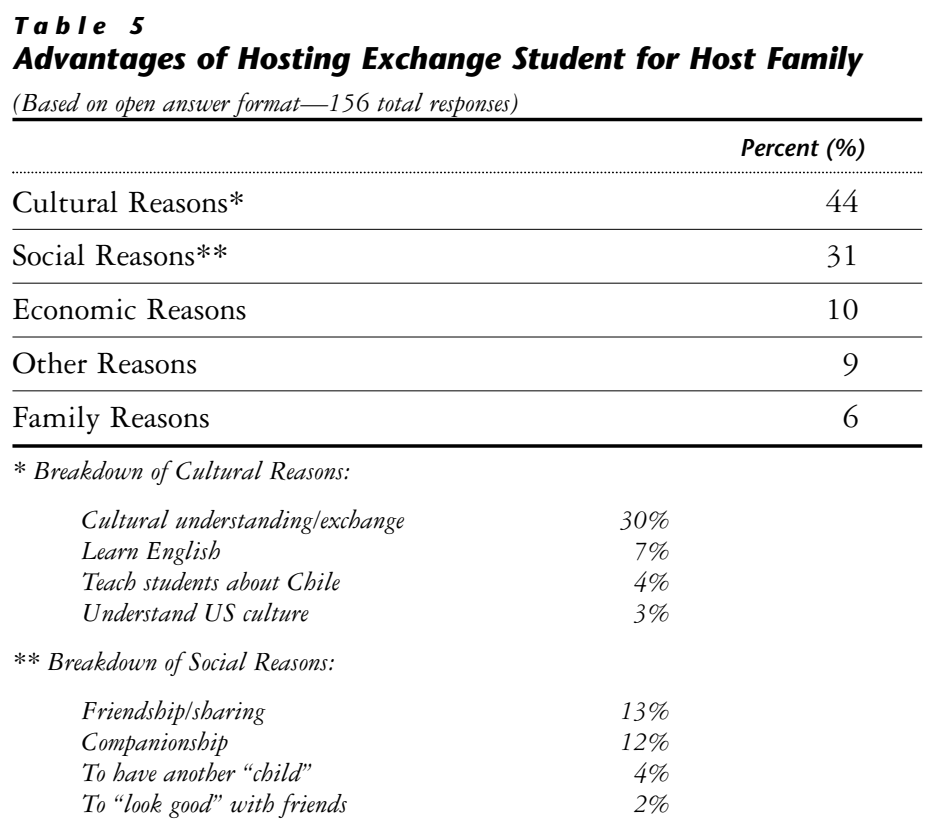

Many less indicated the disadvantages of hosting students. Of those who did respond, the following pattern emerged: about one quarter mentioned the extra work and responsibility involved, and the same amount talked about the loss of privacy and independence. Other disadvantages listed were worrying about when they came home, food issues, telephone use and uncooperative student attitudes.

Interestingly, while cultural reasons were the number one factor given for hosting foreign students, only $10 \%$ indicated cultural differences as a disadvantage. In another question along a similar vein, the families were asked whether they had felt at any time that their study abroad student did not share the same values they did. Again, about $10 \%$ answered in the affirmative. Among the factors most cited were religious differences and different concepts of family and independence. Thus it seems, at least from the families' perspective, that the cultural differences between them and the study abroad students do not create, for the most part, difficulties. Rather, for many of the hosts, the cultural differences are the strongest advantage cited for having a study abroad student. 


\section{Table 6 \\ Disadvantages of Hosting Exchange Student for Host Family}

Based on open answer format (48 responses)

\begin{tabular}{lc}
\hline & Percent (\%) \\
\hline Extra work/responsibility & 26 \\
\hline Loss of privacy/independence & 22 \\
\hline Cultural Differences & 10 \\
\hline Worry & 10 \\
\hline Food issue & 8 \\
\hline Telephone & 6 \\
\hline Not meet contract & 6 \\
\hline Other & 12 \\
\hline
\end{tabular}

The author was most interested in the responses to the questions that dealt with value and belief changes caused by the host family's interaction with the study abroad student. The respondents were asked to evaluate nine "value areas" in terms of whether they had noted a profound personal change, a moderate one, a minimal change, or none at all due to the foreign student presence. Prior to tallying the results, several "value areas" were hypothesized as those that might be most affected by the host family experience. One such area was that of racial views. Considering the relatively closed nature of Chilean society, the fact that over $40 \%$ of the host families had taken in students of either Asian, Black, Native American or Latin American descent might play a part in changing the racial perceptions of host family members. Since many of the program participants hold more "liberal" views than most Chileans concerning the issues of gender equality and sexual orientation, these "value areas" also might have been affected by the presence of a study abroad student.

Discussion of certain controversial issues such as divorce, abortion, political viewpoints, gender issues, etc., also might have affected previously held views of the host family members. After all, about 35\% of the host families said that conversations in their household had become more open as a result of hosting US students. The following are some of the comments made concerning the effect of the students on household conversations: "There is more communication in the family now due to the 
way that North Americans are." "Sometimes they (the students) have a lot to talk about and that brings up new topics," and "We talk more about customs, cultures, different ways of life, etc. now."

The results, as seen in Table \#7, turned out to be different than expected. It appears that the greatest personal change occurred not in the area of specific beliefs, but rather involved the host family member's own perception of Chilean culture. Close to one-half of the respondents indicated that their participation as a host family made them feel a part of Chile's opening up to the world. The next most cited factor was $38 \%$ who claimed that the experience had given them an increased appreciation of Chilean national identity. This was followed by $32 \%$ who had felt a value shift in the image they held of the "other" (foreigner). As can be noted, all three of these categories relate in some degree to Chilean culture/society.

In follow-up interviews, what it meant for the Chileans to have a greater appreciation of their own identity was explored in more depth. What emerged was that no interviewee explained what it meant to be "Chilean" in precise terms. As one host mother said, "I am not sure how to define Chilean culture, but it is very special." Interestingly, their clearest way of defining what it meant to be "Chilean" came from making a comparison with United States culture and with what they assumed people from the United States thought about Chile. As one mother put it, "the student told us how she liked Chile and I came to appreciate how Chileans are.”

The following answers were given to the question of whether the host mother's cultural identity had changed as a result of hosting a US student. One mother said, "No, the student has changed more. However, it helps one a lot when you realize what it is like in the United States and that there are so many things that Chile is lacking. You come to realize that by hosting a North American" Another Mom had the following comment to make, "I have always had the idea that everything in the United States is very modern, it is very pretty. My country is very little, but I love it."

The aspect of Chilean culture most frequently mentioned as positive was the nature of the Chilean family. The hosts considered that in this area Chile definitely was stronger than the United States, which they considered to be "cold" and "too independent." One of the comments along this vein is the following: 
I see that in the United States the people are more liberal and independent. There are advantages and disadvantages of this but I believe that humans, all humans, need "cariño" (affection). There would not be drugs if there were more love in the family. We have these close-knit families and we have the idea that in the United States there are more independent families.

When asked what impression they wanted the American student to gain of Chile during their stay, and how they played a role in providing a better view of Chilean culture, the following comments were made:

I hope that they leave bappy - that they learn what a Chilean family is like, what is a real family. In Chile, we want our children to stay with us until they marry and leave. Of course, there are disadvantages and advantages to the different concepts of family in Chilean and US cultures. In Chile, the family is always together.

Our student has made some comments: she said life here is not so accelerated, and that there is more affection between parents and children. In the US they are alone more. She likes this family environment.

Nonetheless, some host mothers did come to realize that their views of people from the United States often were partially influenced by "stereotypes." Some pointed out that as a result of hosting a US student, they discovered that people from the United States were not really as "cold" as they had thought. They found that the differences were less than they had assumed.

I used to have the idea that people from the US were, how can I explain it, the student was raised more like our system than I had thought. They are less cold then I had thought. Our student, well, she cries, she comes home in the evening. She is affectionate and warm. I thought North Americans were different.

Another theme that emerged from the interviews was the concern that the US students come to realize how modern and civilized Chile really is.

The students come with a preconceived notion that we are different. They think it will be an encounter with people totally different, but 
they find that it is with people who are the same. They might think that we are backwards when they arrive, but by the end of their stay they realize that we are like the Argentines. For example, in Peru or Bolivia you will find a different culture because there is a larger indigenous population there. Here the Indian presence is not so strong-you see it in the raza with darker skin, that is all.

Another mother said:

What I always noticed the most was that they (US students) did not bave a good understanding of this country. They think that we all use feathers, etc. It is not so much a language problem, rather that they think we are all Indians.

Interestingly, the areas in which the least number of host mothers indicated any impact upon their views as a result of the hosting of a foreign student were certain social values. While about $18 \%$ manifested a change in their perspective of democracy and $14 \%$ in their political opinions, less than $6 \%$ were affected in the areas of class issues and gender roles.

\begin{tabular}{|c|c|}
\hline \multicolumn{2}{|c|}{$\begin{array}{l}\text { (Response options were: "No change," "Minimum change," Moderate change," and } \\
\text { "Profound change.") }\end{array}$} \\
\hline \multicolumn{2}{|c|}{$\%$ Indicating Notice of Change } \\
\hline Feeling a part of opening Chile to the world & 47 \\
\hline Increased appreciation of Chilean national identity & 38 \\
\hline Image of the other (foreigner) & 32 \\
\hline Professional expectations of the family & 19 \\
\hline Development of democratic values & 18 \\
\hline Political opinion & 14 \\
\hline Change in views of class & 6 \\
\hline Change in view of gender roles & 6 \\
\hline Change in views of race & 0 \\
\hline
\end{tabular}

Not one host family member mentioned that the experience had 
changed their views on race at all. Whether the respondents felt that they were not racist, and thus did not necessarily need to have any value change in this area, or whether they meant that whatever ideas they might hold did not change is not clear. Since many Chileans proudly mention the lack of racism in Chile, a common viewpoint among Chileans that is often refuted by foreigners living there, the former explanation might be more appropriate to explain the low response rate.

Because of the author's interest in the area of value change and her desire to understand better the low numbers of host family members claiming to have experienced personal change on certain social issues, a more in-depth follow up questionnaire was administered several months later to a somewhat smaller pool of 33 families. This questionnaire focused exclusively on whether their contact and conversations with their exchange students on certain topics had had an impact upon them. The only two choices were "yes" or "no." Twenty issues were listed, including political, religious, cultural, behavioral and social topics.

A similar pattern as in the first questionnaire emerged, with one striking exception. Four out of the five areas in which the most participants indicated experiencing a change (more than one out of four in each case) were no surprise. These areas were in their concept of independence (\#1), their view of Chile (\#4), their view of Chilean politics (\#3-tie) and their idea about the United States (\#3-tie). These responses coincide with the earlier questionnaire results in which general cultural views of both the United States and Chilean cultures were most impacted by the study abroad experience.

The most indicated category-independence-is the predominant characteristic with which the Chileans describe the US students. When the interviewees were asked to indicate the differences, if any, between US and Chilean youth, the following comments were made: "US youth are much more responsible. The youth here are irresponsible. US youth is more independent and organized." Another had this to say about her US host student: "She is not like us, she is very independent. She likes to go far away. We wanted to get together, but she is somewhere else. It is not a problem; we don't want to interfere." Another one said, "US youth are more independent, self-sufficient and mature, Chilean youth are more attached to their parents."

The big surprise was the topic that received the second highest 
number of positive responses - their view of homosexuality. Twenty-seven percent of the people who filled out the questionnaire indicated that their perspective on homosexuality had changed as a result of hosting a US student. While there was no indication as to how their views were modified, it is most likely that, considering the "taboo nature" of homosexuality in Chile, they became more comprehensive and tolerant.

An effort has always been made not to mention to host families the sexual inclination of their students, even in cases where the student was open about their orientation in the housing forms. Several gay students have felt uncomfortable during their stay with the host family because they had to "hide" their true identity. At times, these students had to hear quite derogatory comments about homosexuality, etc. One wonders from this response how much the host families might actually have "picked up" concerning the sexual orientation from their students. Of course, heterosexual students have brought up this theme with their host families during their stay as well. In fact, one homosexual student on the program commented that it was probably easier for heterosexual students than gay students to discuss the topic of homophobia in Chile with their host families.

The five areas in which the least number of respondents indicated experiencing any personal change (less than one out of ten) were their views of relations between men and women, native Americans, abortion, divorce and religion. These responses once again coincide nearly completely with the results from the earlier questionnaire. Perhaps this should not be so surprising since these are all deeply held convictions of which there is quite a bit of cultural conformity among most Chileans. Needless to say, the strong presence of the Catholic Church has had a role to play in the strong convictions regarding divorce and abortion, as well as religion itself.

Views of Blacks, Asians and Hispanics were also quite low in ranking, indicating as in the other questionnaire little value change in these areas. Only $12 \%$ indicated any shift in their views of Black people, $15 \%$ in their opinion of Hispanics from other counties, and $18 \%$ in their perspective of Asians.

Brief mention will be made of the results from the other two areas explored in the initial questionnaire. Concerning the effect of foreign students upon the family dynamics, the following pattern emerged. Only $8 \%$ felt that it had had any influence upon their relationship with their partner, ${ }^{11}$ while $23 \%$ indicated that it had had some impact upon their rela- 
tionship with their own children.

Looking at the household area, the greatest effect of having a foreign student was felt-not surprisingly-in telephone use (62\%). This was followed by the use of other resources such as water, gas and electricity (35\%), all of which are relatively more expensive in Chile than in the US, and tend to be used more sparingly. Other factors that appear to have been impacted include food preparation (29\%) and housecleaning (21\%). Family activities also were mentioned as an arena of change with $36 \%$ indicating some impact. Areas that did not appear to exhibit a significant change included mealtime, and television and music use.

\section{The Effect of the Exchange Experience upon Professors and the University Environment}

University professors were also included in this study. While the relationship between professors and US students might not have the intensity that the host family relationship does, it is nonetheless significant. This is particularly true in Chile since, prior to the arrival of the US students in the early 1990s, there had been very few foreigners studying at the Universidad de Chile and the Pontificia Universidad Católica.

The author was interested in exploring the effects of the foreign students upon several dimensions of the university. The first was in the classroom itself. In what ways, if any, had the environment changed due to the presence of foreign non-degree students in the class? The second was the effect of the US students upon the greater university environment, at least according to the professors' own perspective. The presence of foreign students should affect not only the classroom, but also other aspects of the university, such as course preferences, demand for computers, and even clothing styles. The last area explored how the professors perceived the presence of foreign students on their campus. What were the advantages and disadvantages of having foreign students in their classes? With what issues/value changes/global processes did they associate these non-Latin American, short-term students at the Universidad de Chile and the Universidad Católica?

The administration of the questionnaire was difficult due both to the decentralized nature of the Chilean universities and the campuses' 
large size. Also, there is little tradition in Chile for professors to be asked to fill out questionnaires and surveys, especially those conducted by outsiders. It was decided to target the questionnaire solely to those professors in departments where the most foreign students were concentrated. These were literature, history, political science, esthetics, anthropology, sociology, psychology, geography and the arts.

In total, 137 questionnaires were sent out-64 to the Universidad Católica and 73 to the Universidad de Chile. Only 33 professors answered, giving a response rate of $24 \%$. While this is low, it must be kept in mind that many of the professors who received the questionnaire were either part-time or had had minimal contact with foreign students. It does seem that most of the professors who took the time to fill in the questionnaire had taught foreigners in their classes and wanted to share their experiences and perspectives. As in the case of the families, follow-up interviews were carried out among selected respondents to gain greater understanding of the responses.

Of the respondents, almost $75 \%$ had either studied or taught outside of Chile at some point. Several professors indicated that they "empathized" with how the foreign students felt, since they had gone through a similar process themselves of adjusting to living in a different culture. One professor, who had studied at the University of California at Berkley under the auspices of a Rockefeller grant, made the following comparison:

When I went to the United States a student, everything was made easy for me. When a North American comes here, everything is hard. So logically we have to do what we can to make it as easy as possible for them. It is not a question of money. Our state of development is so precarious, so deficient. For instance, look at the Chilean buses, the students have to live far from the campus and travel by bus every day.

The breakdown of response by department is as follows: eighteen of the respondents hailed from literature, six from history, two from political science, and one each from geography, psychology, art, and anthropology. Two were from miscellaneous areas, including judo! It does not seem that department affiliation affected in any significant way the results. However, one member of the history department at the Universidad de Chile indicated that the study abroad experience might be "easier" for stu- 
dents in history than in literature, since literature deals more with theory and "airy" topics, as she put it.

The questionnaire listed nineteen phrases that could be associated with the presence of foreign students on the campus. The professors were asked to mark any with which they agreed. Table \#8 shows the results. Similar to the families, the greatest number indicated that they associated foreign students with the globalization process. A high number, $56 \%$, also associated them with the diffusion of the Chilean image abroad, while $47 \%$ saw it as a way to overcome Chile's isolation. Also highly ranked were "a more stimulating and active audience" and "broadening of intellectual horizons."

Table 8

Professors' Responses to: "I associate the presence of foreign students with ..."

(33 responses)

\begin{tabular}{lc}
\hline & Percent (\%) \\
\hline Globalization process & 65 \\
\hline A more stimulating audience & 62 \\
\hline Broadening of intellectual horizons & 59 \\
\hline Diffusion of Chilean image abroad & 56 \\
\hline Overcoming Chilean isolation & 47 \\
\hline Racial tolerance & 44 \\
\hline Professional contacts with foreign universities & 41 \\
\hline Economic advantages for the university & 41 \\
\hline Ecumenism & 35 \\
\hline Development of democratic values & 30 \\
\hline Validation of Chilean national identity & 29 \\
\hline International projects for investigation & 26 \\
\hline Professional research of Chile or Latin America & 26 \\
\hline Access to new bibliography & 20 \\
\hline Cultural infiltration & 9 \\
\hline Macroeconomic policy of the Chilean government & 6 \\
\hline Undermining my authority & 0 \\
\hline An artificial imposition in my class & 0 \\
\hline
\end{tabular}


These last two associations were reiterated by another set of responses in the questionnaire. Table \#9 shows the advantages cited by the professors of having foreign students in the classroom. The most frequent response (33\%) given was the foreign students' discipline, approach to work, punctuality, etc. In the interviews, cultural differences in study and work habits came up repeatedly, as can be noted in the following comments:

The Chilean student is not self-responsible. If everyone decides not to go to class, helshe won't, even if this means his grade will go down. It is hard to manage this. All of the society is group-oriented -if someone in the groups tries to do something autonomously they become automatically alone.

It is easier to teach the American than the Chilean because the US student enters to learn while the Chilean student enters because he has to. So there is a problem of interest on the part of the Chileans.

It is not mechanical, but in general the US student is more responsible about going to class, etc. The Chilean students tend to have an attitude in which they exercise their freedom by not attending class regularly. The US student in turn thinks each class has value.

When asked whether these different attitudes towards study had affected the Chilean students, few professors felt that it had. Only five out of the entire pool of respondents answered in the affirmative. One professor said, "you would think that there would be an influence, but I have not observed it." Perhaps the most humorous response was what another professor had to say, "The Chileans, they are lazy, they intrinsically are. Not even God can change them!"

The only change in the Chilean students' classroom performance caused by the foreign student presence seems to have been in an increased competitiveness with the North Americans. As one professor pointed out:

One feels that there is some expectation among the Chileans of how the American group will act. There is also some emulation from the Chileans, as they do not want to be bettered by the North Americans. They want to show that the Chileans have a good level of knowledge 
and know more than the North Americans know. Nonetheless, I feel that this is all done cordially.

While few professors noted any change in the Chilean students' study habits, $15 \%$ indicated that the interaction between the two groups of students was a positive aspect of having exchange students in the classroom. Different factors were mentioned, including how it increased Chilean students' self-esteem, helped them to be less timid, and gave the Chileans more "solidarity." As one professor said, "Both sides win-the US student learns about Chile and the Chilean student comes into contact with people who know the world more broadly."

The quote brings up the "cultural dimension." Several respondents mentioned that the presence of the US students on campus had served to promote the exposure of the Chileans to other cultures and ways of life. In interviews, this phenomenon was mentioned as well. One professor from the Universidad Católica had this to say:

Chile is a very closed society, it is not an immigrant country. Having Blacks, Asians, etc. is a very new phenomenon. Seeing an Asian or a Black is still strange. In the university this is less so, but it is still true. I think that as they incorporate students of different backgrounds, different cultural traditions, different attitudes and ways to be then it will favor greater tolerance. At least they get used to the fact that there are other races, other ways of thinking. This makes us all better.

This same professor felt that over the last few years, as more exchange students arrived, there had been a change in attitude concerning racial tolerance. He felt that it was not so specific that he could explain it well, but that it had became more natural to see students from other places. The presence of students of different ethnic and cultural backgrounds did not attract the Chilean students' attention as much as it first had in the early 1990s.

In Table \#8 the association of exchange students with greater racial tolerance is clearly indicated, with close to half of the professors indicating a positive relationship. It should be noted, however, that this is a different phenomenon than the one related to the host families, who were asked whether they had actually changed their views/opinions concerning 
certain racial and ethnic groups. In fact, among the professors' associations one of the lowest ranked ones was "different perspectives of gender issues," showing, as in the case of the host families, that specific opinions/beliefs seem rarely to be significantly affected by contact with members of other cultures.

Another advantage of US students mentioned by close to $20 \%$ of the professors was the incorporation of different viewpoints and perspectives into the classroom. While the possibility of using the foreign students as a "potential resource" varies from course to course depending on the subject and the class size, there were many professors who explained to the author how they broadened the focus of their class as a result of having foreign students. For instance, the professor of a contemporary Chilean music course began to incorporate more reference to and discussion about United States music and its influence upon Chilean songwriters and musicians.

\begin{tabular}{|c|c|}
\hline \multicolumn{2}{|c|}{ (Based on professors' listing of positive aspects of the presence of foreign students in the classroom) } \\
\hline & Percent (\%) \\
\hline Foreign students' study habits, discipline, punctuality & 33 \\
\hline Incorporation of different viewpoints & 19 \\
\hline Impact on teaching methodology & 17 \\
\hline Interaction with Chilean students & 15 \\
\hline Way to know other cultures, process of globalization & 13 \\
\hline Greater appreciation of our Chilean culture & 1.5 \\
\hline Creates personal and institutional identity & 1.5 \\
\hline
\end{tabular}

The importance of this phenomenon comes through in other parts of the questionnaire as well. Table \#11 shows the ranking given by the professors of the effect of foreign students upon the university environment. As can be seen, the highest-ranked effect was the student perspective on international affairs. Of course, this process is two-way: a professor of contemporary history told the author how he considered that the greatest impact of the abroad experience was upon the US students' views of their own nation's policy to Latin America. He said: 
First of all, the horizon of the US student changes. US students have a very specific and concrete vision of Chile. They are usually moderate and critical at the same time. But they usually become very critical of the US State Department and its policy. This is a constant with all the exchange students. Maybe it has something to do with my course. They say that the US government is losing a chance to be a good friend with Latin America. It is curious how they immediately become critical of US policy.

\section{Table 10 \\ Professors' Ranking of the Impact of Foreign Students upon the University}

\begin{tabular}{lc}
\hline \multicolumn{3}{c}{ Based on ranking scale of $\mathbf{1}$ to 8, with $\mathbf{8}$ indicating the most influence } \\
\hline In student perspectives on international affairs & 4.39 \\
\hline In course preferences & 4.33 \\
\hline $\begin{array}{l}\text { In international professional possibilities } \\
\text { for Chilean students }\end{array}$ & 3.89 \\
\hline In the competition for limited resources (computers, etc.) & 3.75 \\
\hline $\begin{array}{l}\text { In the social activities at student centers } \\
\text { and meeting areas }\end{array}$ & 3.75 \\
\hline $\begin{array}{l}\text { In the demands for clear guidelines in course } \\
\text { evaluation and grading }\end{array}$ & 2.45 \\
\hline In student extracurricular activities & 2.35 \\
\hline Creates personal and institutional identity & 1.5 \\
\hline
\end{tabular}

Another commonly cited attribute of the foreign student presence was its effect upon teaching methodology. Seventeen percent of professors listed that they had in some way changed their methodology as a result of teaching foreign students. In responses to two other questions, the impact upon teaching methodology was even more notable. When asked if they had incorporated new themes in their class due principally to the presence of foreign students, 30\% indicated "yes." Almost the same percentage, $32 \%$, answered in the affirmative to the question, "Has the presence of foreign students influenced your teaching methodology?"

Professor Guerra of the History Department of the Universidad de Chile felt that, "teaching exchange students makes me work harder, try 
harder. I try to reach their souls. That is good for me." In particular, he noted changes in three areas: "I have had to incorporate more graphic material. I have to do a very good mental exercise, be bilingual, to explain things to the students sometimes. I have also been able to incorporate a more participative methodology since the North American students ask more questions."

Interestingly, this professor as well as some of the others concerned with helping the US students strongly advocated a different treatment for the study abroad students. Table \#11 shows the percentage of respondents who indicated that they treated the US students in a different manner than the Chileans. The figures range from $63 \%$ who claimed to treat the exchange students differently in the explanation of the course to only $7 \%$ who said they used the blackboard differently.

Perhaps the most interesting statistic is that over half feel that their personal relations are different with the foreign students. One professor explained that at least from his perspective the US students were more open and willing to establish a relationship outside of the classroom. He felt that this might be at least partially due to the following:

The foreigner is outside of his natural environment. What this does is that if you are in your own environment you go to class and that is that. But the US students attach themselves to the professor, come after class to talk, etc. and that is nice. The North Americans talk more than the Chileans after class.

Another important finding involved language use in the classroom. Almost one-third of the professors indicated that they had altered their language use due to the presence of the foreign students. Some of the professors who know English have even explained material in English in the classroom so that the students would better understand. There are even some who allowed students to take the examinations and/or write their papers in English if they want. While many proponents of the "direct exchange" programs oppose this policy, feeling that it defeats the purpose of the academic program, there are quite a few Chilean professors who adamantly argue the opposite. One professor who often has more foreign than native students in his classes explained it this way:

A few years ago heads of several of the exchange programs here had a 
meeting with me criticizing me because I let the students do their papers and examinations in English. To me, I don't care if they speak Spanish well or badly. The important thing is that they do the analysis. I am not sure if I convinced the authorities, but the curious thing is how many of the students write in Spanish anyway. Usually they try to write in Spanish and then if they feel that they cannot express their point they write in English. I really believe that it is important that the students be allowed to write in English in some cases.

\section{Table 11 \\ Percentage of professors treating foreign students in a dif- ferent manner than Chilean students}

(Derived from a self-evaluation based on a three-answer alternative of "yes, treated them differently," "never treated them differently," and "never treated them differently but I should have")

\begin{tabular}{lc}
\hline & Percent (\%) \\
\hline In explaining course structure and expectations & 63 \\
\hline In relating to them & 62 \\
\hline In examinations & 52 \\
\hline In explaining course material & 45 \\
\hline In oral work & 45 \\
\hline In written work & 43 \\
\hline In planning with the TA (if relevant) & 38 \\
\hline In language use & 32 \\
\hline In evaluating their work & 29 \\
\hline In using outlines & 23 \\
\hline In organizaing work groups & 19 \\
\hline In using the blackboard & 7 \\
\hline
\end{tabular}

This lack of concordance between the program's goals of total immersion and some professors' desires to "help" the foreign students by giving them special treatment illustrates a reality, at least in the Chilean context, which needs to be addressed. This difference between program philosophy and practice can be partially attributed to the lack of incorporation of the professors in the process of internationalizing the university. It seems that the university authorities gave little policy guidelines to the professors. They allowed foreign students to enroll in regular university 
courses, but provided the professors with minimal, if any, preparation.

At a meeting the author organized along with several colleagues, this issue was explored in more depth. Professors from both the Universidad de Chile and the Universidad Católica were present. When they were asked, "Has there ever been a time when you were told about or incorporated into the process of receiving the foreign students?" the following comments were made: "No. Never. It seems to be up to each professor to try to do it in his/her own way. But it would be better if we were not alone. I miss an orientation from the institution that explains to the professor what to do." Another had this to say: "Sometimes I have gotten extra funds for photocopies, etc. but we never did get extra information about the program." Yet another said: "I never knew that it was an institutional project. I was never told about it. If it corresponds to a project, there should be additional material given to the professors and we should be taught "tricks" of better teaching the foreign students."

The importance of assisting the professors in the teaching of foreign students can be illustrated by the following example: only two professors claimed to have changed their use of the blackboard as a result of having foreign students in the classroom, but many of the students indicated that increased use of the blackboard, especially the writing down of terms that were difficult to understand, would have assisted them greatly in understanding the professors and the content of the courses.

\section{Conclusions}

The premise of this study is that not only US students but also members of the host society are affected by the study abroad experience. This might be particularly true in a country such as Chile that has been relatively isolated. The results of this study seem to indicate that both the Chilean host families and the Chilean university professors did undergo some transformations/changes as a result of their relationship with the US students.

However, the actual dimensions of the changes that emerged from the responses were different than might have been expected. In the case of the US students themselves, the experience was more challenging to their personal beliefs than they had anticipated. Whereas they expected to have the greatest difficulty in adjusting to the use of Spanish, many found that 
cultural differences were more stressful than linguistic ones. Particularly notable were the differences in views of class and race between Chile and the United States. Issues such as time use, food patterns and sexism were also frequently mentioned as difficult. The university environment as well was considered daunting to many, particularly the lack of clear guidelines, schedules and the lecture style used by many Chilean professors.

By the end of their stay, many of the US students continued to hold quite favorable impressions of the Chileans, feeling that overall they were friendly and hospitable. Nonetheless, some felt that the differences between themselves and the host nationals proved greater than their first impression. Quite a few of the US students mentioned the closed nature of Chilean society and its ethnocentrism. Others looked more within themselves, recognizing that it was harder to be open-minded then they had first thought.

Interestingly, for the host families a somewhat similar process occurred, although the fact that they were "at home" meant that the impact was not as intense as it was for the students themselves. The most significant result of hosting a US student upon the host families appears to have been in reaffirming their own sense of being Chilean and in gaining a deeper appreciation of their own culture. This was most notable in the area of family values, which were frequently cited by the host families as a positive aspect of Chilean culture. Another area that appears to have been markedly affected was the host families' view of the "other," i.e., of the United States and its "culture." In fact, this effect was the advantage most frequently mentioned by host mothers of having a US student. However, in more specific issues involving values and/or beliefs, few felt that their perspective had changed in any way by the presence of US students in their household, except with respect to their opinion of homosexuality.

Of the three groups studied, it was perhaps the professors who noted the most value/opinion changes due to the presence of the US students. They seemed to feel overall that both the classroom environment as well as the university as a whole had been affected in significant ways by the recent presence of US students. They most noted the students' contribution, albeit unintended, to increasing racial tolerance, or at least their getting the Chileans more accustomed to being with peoples of other ethnic backgrounds, religions and nationalities. They also felt that, to some degree, it had served to broaden the dialogue in the classroom and to affect 
both US and Chilean students' perspectives on certain issues.

Within the classroom, they noted differences in the attitudes toward study and work habits between the United States and Chilean students. Once again, however, the permeance of cultural patterns emerged because they did not feel that the Chileans had changed in any significant way due to having more "disciplined" foreigners in the class. Quite a few of the respondents indicated that it was easier to teach the US students than the Chilean ones.

The results from all three groups examined in this paper demonstrate one salient fact: cultural patterns are firmly rooted within most individuals, and not as open to modification as many people assume. This is not to say that culture is not flexible and open to change. Rather, it is to present the caveat that one should not assume that cultural change will necessarily occur as a result of a study abroad experience.

In these days, when the focus is increasingly upon "internationalizing the university" and the process of "globalization," attention also needs to be given to cultural specifics. Just because more students can study abroad in more places than ever before, it does not mean that the experience will be any easier. In fact, to a certain extent it might be even harder. The advent of e-mail, the proliferation of cheap airplane flights, the spreading of US culture to many nations, all give the US study abroad student the impression that the cultural differences are less than they really are. Some scholars have even posited that globalization leads indeed to the opposite phenomenon at the same time-namely, a greater appreciation of ones owns specific culture.

Perhaps one of the greatest contributions that overseas programs can make to promoting world peace and understanding is to foster that crucial but difficult ability to maintain one's own cultural affiliation while at the same time appreciating the richness of other cultures. As practitioners in the field, we should try to engender among the students, and ourselves as well, the capacity to remain true to our own values while profoundly understanding those of another culture. The true challenge of study abroad is not to attempt to remain the same, nor to become different. Rather, the challenge is to contact and affirm our common humanity. 


\section{Not e s}

1 The author had the invaluable help of several individuals. Danna Lee's cross-cultural expertise, computer skills and insightful suggestions contributed immensely to the entire project. Maria Isabel Mizon of the Pontificia Universidad Católica de Chile provided the "Chilean perspective," particularly in drafting the professors' questionnaire. Peter Frerichs spent numerous hours interviewing the Chilean host families. Finally, Briggitta Muñoz devoted much time to the inputting of the data.

2 Stephen Bochner and Adrian Furnham, Culture Shock (London: Routledge Press, 1986), p. 39.

3 Ibid, p. 44.

4 At one point, Buenos Aires had more foreign born than native residents. Particularly strong was Italian immigration. The migrants were known as "swallows," since they would often travel back and forth from Argentina to Italy several times in their lifetime. Argentina was also the host to a large stream of Jewish migrants as well.

5 Chileans are proud to have been the first nation in the Americas to outlaw slavery. In any case, the numbers of black slaves in Chile was quite insignificant, although some scholars have noted a black influence in some of the colonial music and dance.

6 For more on this interesting topic, see Sonia Montecino, Madres $y$ Huachos: Alegoria del Mestizaje Chileno (Santiago: Editorial Sudamericana, 1996).

7 This figure is partially due to Latin American definitions of race, which are different than North American ones. In Latin America ethnic affiliation is defined more by cultural than racial factors. The most recent Chilean census (1992) found over that one million Chileans above the age of 14 claimed to be indigenous.

8 The number of Chilean professionals who have received training as a result of grants and bilateral exchange programs is quite large. For more information on this topic, see Skye Stephenson, "Educational Exchanges in Chile," Ph.D. dissertation (The Fletcher School of Law and Diplomacy, 1986).

9 In this study, the focus is on the two oldest and best-known universities in Chile: the Universidad de Chile and the Pontificia Universidad Católica de Chile. Nonetheless, it is important to note that in recent years 
there has been a blossoming of private universities, some of which are also hosts to overseas students.

10 Both the SUNY-Plattsburgh and the Council program grew quite rapidly. For instance, the Council program started with less than fifteen students the first semester but two years later had grown to over thirty students per semester. By 1995, around sixty students per semester were participating.

11 It should be pointed out that $36 \%$ indicated that this question was not applicable to their situation. This shows the high number of widowed/separated/single women who participate as host mothers. 